\title{
Preoperative multidisciplinary program for bariatric surgery: a proposal for the Brazilian Public Health System
}

\author{
Elinton Adami CHAIM, José Carlos PAREJA, Martinho Antonio GESTIC, \\ Murillo Pimentel UTRINI and Everton CAZZO*
}

Received 7/8/2016 Accepted 12/9/2016

\begin{abstract}
Background - Bariatric surgery has become the gold standard treatment for morbid obesity, but access to surgery remains difficult and low compliance to postoperative follow-up is common. To improve outcomes, enable access and optimize follow-up, we developed a multidisciplinary preoperative approach for bariatric surgery. Objective - To determine the impact of this program in the outcomes of bariatric surgery in the Brazilian public health system. Methods - A prospective evaluation of the individuals who underwent a preoperative multidisciplinary program for bariatric surgery and comparison of their surgical outcomes with those observed in the prospectively collected historical database of the individuals who underwent surgery before the beginning of the program. Results - There were 176 individuals who underwent the multidisciplinary program and 226 who did not. Individuals who underwent the program had significantly lower occurrence of the following variables: hospital stay; wound dehiscence; wound infection; pulmonary complications; anastomotic leaks; pulmonary thromboembolism; sepsis; incisional hernias; eventrations; reoperations; and mortality. Both loss of follow-up and weight loss failure were also significantly lower in the program group. Conclusion - The adoption of a comprehensive preoperative multidisciplinary approach led to significant improvements in the postoperative outcomes and also in the compliance to the postoperative follow-up. It represents a reproducible and potentially beneficial approach within the context of the Brazilian public health system.
\end{abstract} HEADINGS - Obesity. Bariatric surgery. Gastric bypass. Public health. Preoperative care.

\section{INTRODUCTION}

Obesity has become a worldwide public health concern in the last decades. In 2014, according to the World Health Organization (WHO), more than 1.9 billion adults, 18 years and older, were overweight; of these over 600 million were obese. This high prevalence provoked the curious phenomenon that the majority of the world's population nowadays lives in countries where overweight and obesity kills more people than underweight ${ }^{(32)}$. Brazil is nowadays the second country in which more bariatric surgeries are yearly performed, only behind the United States of America (USA) ${ }^{(27)}$.

Bariatric surgery has become the gold standard treatment for morbidly obese subjects as it leads to significant weight loss and control of comorbidities in most cases. Overall impact of surgery on long term mortality reduction has already been observed on obese patients with $40 \%$ reduction on all causes mortality, $56 \%$ on coronary heart disease, $92 \%$ on diabetes complications and $60 \%$ on any type of cancer ${ }^{(1)}$. However, due to the extreme raise in obesity's prevalence, only a minority of the obese population has been able to reach surgical treatment. In fact, less than $0.7 \%$ of the overall obese population actually undergoes surgery ${ }^{(4)}$.

Bariatric surgeries often lead to great changes in lifestyle that are essential to good results. They require compliance to clinical, psychological, and nutritional follow-up, chronic prescription medicine usage, and regular physical activity ${ }^{(9,10,12)}$. To achieve such compliance is usually a difficult task, since adhesion to long-term therapies commonly presents poor results ${ }^{(31)}$.

Based on the hypothesis that part of this problem may be related with the necessity of a more cautious and prolonged preoperative period, we developed a multidisciplinary preoperative assessment program, whose primary goals were: 1) preoperative weight loss; 2) reinforcement of nutritional assistance; 3) careful management of psychological issues; 4) education about basic home nursing notions; 5) emphasizing of the importance of continuous postoperative follow-up; 6) basic educational principles of obesity and its hazards; 7) emphasis on the role played by the individual's family in all of the phases of the treatment.

This study sought to determine the impact of this program in the outcomes of bariatric surgery in the setting of a public Brazilian hospital from a historical perspective.

\section{METHODS}

This is a descriptive population study which aims to prospectively evaluate the individuals who underwent a preoperative multidisciplinary program for bariatric surgery (Program Group - P) and compare their surgical outcomes with those observed in the prospectively collected database of the individuals who underwent 
surgery before the beginning of the program (NP). Group P underwent surgery from 2003 through 2007; group NP underwent surgery from 1998 through 2002. Patients were followed-up for 18 months following surgery.

The setting of this study is a public tertiary university hospital. This study underwent evaluation and was approved by the local Research Ethics Board. The surgical technique adopted was the Roux-en-Y gastric bypass (RYGB), and all surgeries were performed by the same team. RYGB was indicated according to the National Institutes of Health Consensus Statement criteria. Surgery was indicated for individuals who were obese for at least five years, with at least two unsuccessful attempts to conservative treatment, with a body mass index (BMI) equal or above $40 \mathrm{~kg} / \mathrm{m}^{2}$, or equal or above $35 \mathrm{~kg} / \mathrm{m}^{2}$ associated with obesity-related comorbidities ${ }^{(14)}$. Estimation of sample size was performed using single proportion formula with $95 \%$ confidence interval. Precision was set at 5\% and the calculated sample size was 226 . Inclusion criteria were: individuals aged from 18 to 65 years old, which underwent RYGB. Exclusion criteria were: subjects who belonged to vulnerable groups (mentally ill, institutionalized or aged below 18 years old); refusal to take part in the study.

The studied variables included: age, gender, body mass index (BMI), weight, excess weight loss (EWL), and percentage of excess weight loss $(\% \mathrm{EWL})$; the main outcomes and complications evaluated were: hospital stay; wound dehiscence; wound infection; pulmonary complications; anastomotic leaks; pulmonary thromboembolism; sepsis; incisional hernias; eventrations; reoperation rate; and mortality.

We also assessed the presence of postsurgical weight loss failure (defined by a $\%$ EWL below $50 \%$ one year after surgery as previously described by Reinhold ${ }^{(28)}$ ) and follow-up at 18 months (defined by compliance to all of the appointed postsurgical consultations).

\section{Standard Preoperative Assessment in the Non-Program Group}

Individuals who underwent surgery before the initiation of the preoperative multidisciplinary program received the standard preoperative assessment, which consisted in a first consultation appointed by the regional health department that was carried out by a surgeon. The patient then underwent a single consultation with clinical psychologist, nutritionist and endocrinologist. Following these consultations and the results of preoperative examinations, the individuals underwent surgery.

\section{Preoperative Multidisciplinary Program Rationale}

The program basically consists in a systematic outpatient multidisciplinary assistance that lasts for a non predetermined period of time. The obese patients that are longing for treatment are listed by the regional department of Public Health and by our own service, where they are attended yearly in public events that we promote. Every week, about 20 patients are called for a summoning which consists in the first individual consultation; this is called the "new case consultation". Then, individuals are subdivided in groups which are attended every week; each group is composed by about 20 to 30 individuals. They then undergo weekly multidisciplinary consultations which are carried out respectively by physician/surgeon, nurse, nutritionist, psychologist and physical trainer; these professionals make explanations about the impact of obesity in their respective fields of work and the overall importance of the treatment. All of the consultations take place at the same place.
The individuals are obliged to attend all the appointed consultations and keep a regular loss of weight during the follow-up. For individuals who are not superobese, a weight loss of $10 \%$ to $20 \%$ is required before surgery. When superobesity is present, a BMI below $50 \mathrm{~kg} / \mathrm{m}^{2}$ must be reached.

\section{Surgical Technique and Postoperative Protocol}

The individuals in both groups underwent open Roux-en-Y gastric bypass (RYGB). The main features of the RYGB were a $30 \mathrm{~mL}$ gastric pouch, a $100 \mathrm{~cm}$ biliopancreatic limb, a $150 \mathrm{~cm}$ alimentary limb, and a common limb consisting of the remainder of the small intestine. The same postoperative protocol was used in both groups.

\section{Statistical analysis}

The univariate analysis of categorical variables was carried out through chi-square and Fisher's exact tests. For comparisons of continuous measures, Mann-Whitney test was used. The significance level adopted was $5 \%$ ( $P$-value $<0.05)$. For the execution of analysis, it was used Statistic Analysis System (SAS) software for Windows version 9.2 .

\section{RESULTS}

The total number of participants in this study was 402. The non-program (NP) group was composed by 226 individuals who underwent RYGB between July 1998 and December 2002. The Program (P) Group was composed by 176 individuals who underwent RYGB between February 2003 and July 2007. There were 148 individuals who were firstly attended at the Program, but did not reach the mandatory weight loss and therefore have not undergone surgery at this point. These individuals were invited to remain in the program until their weight loss goals could be achieved.

There was no statistical difference regarding age, gender and initial BMI between groups P and NP. Table 1 summarizes the main demographic and anthropometric characteristics of the studied subjects.

TABLE 1. Main characteristics of the subjects at baseline

\begin{tabular}{lccc}
\hline & $\begin{array}{c}\text { Program } \\
\text { Group }\end{array}$ & $\begin{array}{c}\text { Non-Program } \\
\text { Group }\end{array}$ & Value of $\boldsymbol{P}$ \\
\hline Age (years) & 40.5 & 40 & 0.763 \\
$\begin{array}{l}\text { Gender } \\
\text { Female }\end{array}$ & $130(73.9 \%)$ & $175(77.4 \%)$ & 0.407 \\
$\quad$ Male & $46(26.1 \%)$ & $51(22.6 \%)$ & \\
BMI at admittance $\left(\mathrm{kg} / \mathrm{m}^{2}\right)$ & $50.6 \pm 8.4$ & $51.8 \pm 9.5$ & 0.201 \\
BMI at surgery $\left(\mathrm{kg} / \mathrm{m}^{2}\right)$ & $42.1 \pm 5.6$ & $51.8 \pm 9.5$ & $<0.001$ \\
Weight at admittance $(\mathrm{kg})$ & $135 \pm 28.7$ & $137.6 \pm 29,4$ & 0.412 \\
$\begin{array}{l}\text { Weight at surgery }(\mathrm{kg}) \\
112.3 \pm 21.1\end{array}$ & $137.6 \pm 29.4$ & $<0.001$ \\
$\begin{array}{l}\text { Excess weight at } \\
\text { admittance }(\mathrm{kg})\end{array}$ & $68.2 \pm 24.4$ & $69.2 \pm 32.6$ & 0.323 \\
$\begin{array}{l}\text { Excess weight at } \\
\text { surgery (kg) }\end{array}$ & $45.6 \pm 16.4$ & $69.2 \pm 32.6$ & $<0.001$ \\
\hline
\end{tabular}

BMI: body mass index 
The individuals of the $\mathrm{P}$ group achieved a mean preoperative weight loss of $22.6 \pm 12.2 \mathrm{~kg}$, leading to a decrease in mean BMI from $50.6 \pm 8.4$ to $42.1 \pm 5.6$, which represented a mean $32.5 \pm 11 \%$ decrease in excess weight loss. The prevalence of hypertension among these individuals decreased from $70 \%$ at admittance to $20 \%$ at surgery, whereas the prevalence of diabetes decreased from $52 \%$ to $38 \%$ in the same period. Table 2 describes the changes in these anthropometric and clinical features in the individuals of the $\mathrm{P}$ group. The mean time spent in the program by the individuals in the group $\mathrm{P}$ was $12.6 \pm 7$ weeks.

TABLE 2. Anthropometric and clinical characteristics at admittance and at surgery of the individuals who underwent the preoperative multidisciplinary program

\begin{tabular}{lccc}
\hline & Admittance & Surgery & Value of $\boldsymbol{P}$ \\
\hline BMI $\left(\mathrm{kg} / \mathrm{m}^{2}\right)$ & $50.6 \pm 8,4$ & $42.1 \pm 5.6$ & $<0.001$ \\
Weight $(\mathrm{kg})$ & $135 \pm 28.7$ & $112.3 \pm 21.1$ & $<0.001$ \\
Excess weight $(\mathrm{kg})$ & $68.2 \pm 24.4$ & $45.6 \pm 16.4$ & $<0.001$ \\
Hypertension & $123(69.9 \%)$ & $35(19.9 \%)$ & $<0.001$ \\
T2DM & $92(52.3 \%)$ & $67(38.1 \%)$ & $<0.001$ \\
\hline
\end{tabular}

BMI: body mass index; T2DM: type 2 diabetes mellitus

Regarding surgical outcomes and complications, there were significant differences between groups $\mathrm{P}$ and NP in the following occurrences: hospital stay ( $4.1 \pm 0.3$ vs $6.2 \pm 2.4$ days; $P=0.031$ ); wound dehiscence $(11.4 \%$ vs $20.3 \% ; P=0.016)$; wound infection $(1.7 \%$ vs $6.2 \% ; P=0.027)$; pulmonary complications $(1.1 \%$ vs $5.3 \% ; P=0.024)$; anastomotic leaks ( 0 vs $4 \% ; P=0.008)$; pulmonary thromboembolism ( 0 vs $4 \% ; P=0.008$ ); sepsis ( 0 vs $2.2 \% ; P=0.019$ ); incisional hernias ( $8.5 \%$ vs $34.5 \% ; P<0.001)$; eventrations ( 0 vs $2.2 \% ; P=0.019)$; and reoperations $(1.1 \%$ vs $6.2 \% ; P=0.02)$. There was no mortality in the P group, whereas in the NP group, it was observed a $4.4 \%$ mortality $(P=0.05)$. Table 3 details these findings.

There were significant differences between the groups regarding postsurgical weight loss failure rate and compliance to follow-up. In the P group, $8.5 \%$ presented failure, while in the NP group this occurred in $20.3 \%(P=0.001)$. Loss of compliance to follow-up at 18 months following surgery was also significantly lower in the $\mathrm{P}$ group $(7.4 \%$ vs $33.2 \% ; P=0.0001)$.

TABLE 3. Comparison of surgical outcomes and complications between the program and non-program groups

\begin{tabular}{lccc}
\hline & Program & Non-program & Value of $\boldsymbol{P}$ \\
\hline Hospital stay (days) & $4.1 \pm 0.3$ & $6.2 \pm 2.4$ & 0.031 \\
Wound dehiscence & $20(11.4 \%)$ & $46(20.3 \%)$ & 0.016 \\
Wound infection & $3(1.7 \%)$ & $14(6.2 \%)$ & 0.027 \\
Pulmonary complications & $2(1.1 \%)$ & $12(5.3 \%)$ & 0.024 \\
Pulmonary & 0 & $9(4 \%)$ & 0.008 \\
thromboembolism & 0 & $5(2.2 \%)$ & 0.019 \\
Sepsis & 0 & $9(4 \%)$ & 0.008 \\
Anastomotic leak & $15(8.5 \%)$ & $78(78(34.5 \%)$ & $<0.001$ \\
Incisional hernia & 0 & $5(2.2 \%)$ & 0.019 \\
Eventration & $2(1.1 \%)$ & $14(6.2 \%)$ & 0.022 \\
Reoperations & 0 & $10(4.4 \%)$ & 0.05 \\
Mortality & & & \\
\hline
\end{tabular}

\section{DISCUSSION}

An adequate preparation for surgery has been an ever present point of concern regarding bariatric surgery. Over time, the surgical risk for bariatric surgery presents an ever decreasing trend, so that nowadays, for the majority of the obese population, it is clearly safer to undergo surgery than to maintain obesity. On the other hand, there are few improvements reported in the subject of compliance to follow-up ${ }^{(7,9,19)}$. Despite the great amelioration of outcomes observed in the last decades, surgical risk, although low, is still significant, especially in some specific groups of patients (i.e. elderly, severe chronic disease carriers etc) ${ }^{(6,24)}$.

In Brazil's public health system, we struggle against specific factors that are not so prominent in other countries. In Brazil, the public system is designed to be universal, i.e. attend the whole population. However, the most financially favored population can afford to be attended by private health providers. In fact, a study showed that $27.9 \%$ of the Brazilian population had access to private services $^{(20)}$. So, in the public system we attend a population who has poor financial and funding capability, to the point that some patients cannot afford even transport tickets to the destination service. Regarding cultural characteristics, a study estimated a prevalence of functional illiteracy (individuals who do not have skills to interpret a simple text) of about $34.3 \%$ in the Brazilian population, besides the $13 \%$ prevalence of complete illiteracy (individuals who are unable to decode words and phrases) ${ }^{(17)}$. So, we handle with such a needy and illiterate population that needs great help to have the minimal conditions to achieve satisfactory postoperative outcomes and follow-up.

Another point is that, despite the universal access to public health, there is a huge incapacity to attend certain demands, of which, bariatric surgery is one the most affected. There are only about 50 public hospitals in the entire Brazilian territory in which bariatric surgeries are performed ${ }^{(18)}$, although recent studies observed that the obesity prevalence in Brazil is $17.9 \%$, which corresponds to almost 30 million obese people ${ }^{(23)}$. Only about $10 \%$ of all bariatric surgeries in Brazil are performed in public services ${ }^{(18)}$.

The idea behind the establishment of the multidisciplinary preoperative approach was to aggregate and enable access to a larger number of individuals and therefore create a situation where those more apt to undergo surgery and follow the prescript recommendations would receive the surgical treatment, leading to better outcomes and fewer complications in all of the dimensions possibly affected. It may be argued that this process can alienate some candidates however, since our service works at maximum surgical capacity, a significant number of individuals would not otherwise undergo surgery independently of the program existence. So, in a situation of limited sources, this is a way to improve results and avoid unnecessary costs with avoidable complications. In Canada, Halloran et al. ${ }^{(16)}$ observed that low income obese individuals tend to be older, heavier, and have greater comorbidity profile; moreover, these authors observed that, within a publicly funded and universally accessible regional obesity program, lower income status patients were less likely to be approved for bariatric surgery. Even in Sweden, Memarian et al. ${ }^{(22)}$ observed that individuals in the lowest socioeconomic groups undergo bariatric surgery less often than those with intermediate income and educational level, although previous research has shown that those with low socioeconomic status have the highest rates of morbid obesity. Analyzing data from the 2005-2006 National Health and Nutrition Examination Survey 
(NHANES), Martin et al. ${ }^{(21)}$. also observed that, in the USA, socioeconomic factors play a major role in determining who does and does not undergo bariatric surgery, despite medical eligibility. It is very likely that, in Brazil and other low and middle-income countries, we handle with a harder social context and the difficult to access public health service represents a huge concern.

There is evidence about the benefits achieved by means of preoperative weight loss. Benotti et al. ${ }^{(5)}$, in a prospective study enrolling candidates to gastric bypass, observed significant decreases in perioperative complications and hospital stay in individuals who achieved $10 \%$ of excess weight loss before surgery. Alami et al. ${ }^{(2)}$, in a prospective study enrolling candidates to gastric bypass, reported significant decreases in hospital stay and postoperative excess weight loss, although there was no difference regarding surgical complications. In a prospective study, Still et al. ${ }^{\left({ }^{30}\right)}$ observed that individuals who achieved a $5 \%$ to $10 \%$ excess weight loss before the procedure presented lower hospital stay and faster postoperative weight loss. Riess et al. ${ }^{(29)}$, in a retrospective analysis, concluded that a preoperative weight loss led to a significantly lower rate of surgical complications. A retrospective study by Alvarado et al. ${ }^{(3)}$ revealed that preoperative weight loss was associated with lower operative time and greater postoperative weight loss. Fris ${ }^{(13)}$ has shown that cautious preoperative nutritional counseling could lead to weight loss and decrease in the liver volume before surgery, leading to less difficulty to perform surgery.

On the other hand, Conaty et al. ${ }^{(8)}$, in a database analysis, observed that a preoperative weight loss program did not result in significantly greater weight loss or comorbidity resolution; the authors also comment that the value of a mandatory weight loss program must be weighed against the potential loss of bariatric surgery candidates. Parikh et al. ${ }^{(25)}$, in a randomized trial enrolling candidates to laparoscopic adjustable gastric banding (LAGB), observed that a mandatory medically supervised weight loss program does not appear to confer additional benefit as compared to the standard preoperative bariatric surgery protocol in terms of weight loss and behavioral outcomes after LAGB.

All of these studies analyzed programs that focused on the isolated preoperative weight loss; there are a few studies evaluating more integrative preoperative approaches. Delgado-Floody et al. ${ }^{(11)}$ analyzed the postoperative outcomes of 21 individuals who underwent a preoperative 4-month program that enrolled physical exercise, counseling and nutrition education, three times a week; it was observed a significant improvement in the preoperative conditions of obese candidates for bariatric surgery and a decrease in the risk of morbidity and mortality. Patel et al. ${ }^{(26)}$, in a matched-cohort study comparing the weight loss outcomes of obese individuals who underwent a preoperative multidisciplinary program, composed by nutritionist, physician, and physical trainer, and candidates who underwent surgery without taking part in this program; patients which received multidisciplinary management input prior to RYGB lost significantly more weight at 6 and 12 months than those who did not receive. Our proposal is even more integrative, since it encompasses other dimensions of the attendance, such as education about obesity and surgical treatment, the importance of compliance to follow-up, psychological topics, nursing and nutritional notions, and family enrollment in the whole process. Moreover, a factor that must be weighed and is hard to evaluate is the influence of the social environment in the surgical and medical outcomes. A recent study carried out by the GlobalSurg Collaborative group revealed that mortality following emergency abdominal surgery is three times higher in low-income compared with high-income countries ${ }^{(15)}$.

This study has some limitations. Firstly, this is a comparison of data obtained by different ways (prospectively collected database vs. directly longitudinal population study), a fact that limits some of the possible analysis, since the data from the database may be of poorer quality. Another important factor is that the present study compares outcomes from two time periods that are very different, due to the constant evolution of the bariatric surgical techniques. Although the basic technique and surgical team were the same, it is indubitable that surgery became safer in the last decades and that later patients benefited from the positive effects of the surgical learning curve.

It is our belief that this concept of preoperative approach presents strong medical and social implications, and it is a possible way to optimize costs and potential of attendance, as well as maximize access, in public health systems of low and middle-income countries.

\section{CONCLUSION}

The adoption of a comprehensive preoperative multidisciplinary approach led to significant improvements in the postoperative outcomes and also in the compliance to the postoperative follow-up. It represents a reproducible and potentially beneficial approach within the context of the Brazilian public health system.

\section{Statement of Informed Consent}

Informed consent was obtained from all individual participants included in the study.

\section{Statement of Human and Animal Rights}

All procedures performed in studies involving human participants were in accordance with the ethical standards of the institutional and/or National Research Committee and with the 1964 Helsinki declaration and its later amendments or comparable ethical standards.

\section{Authors' contributions}

Chaim EA designed the study and created the concept which was evaluated. Pareja JC contributed relevant intellectual inserts and provided critical revision. Gestic MA contributed clinical assistance to the individuals enrolled in the study. Utrini MP contributed clinical assistance to the individuals enrolled in the study. Cazzo E performed the statistical analysis and wrote the article. 
Chaim EA, Pareja JC, Gestic MA, Utrini MP, Cazzo E. Programa multidisciplinar de assistência pré-operatória para cirurgia bariátrica: uma proposta para o Sistema Público de Saúde do Brasil. Arq Gastroenterol. 2017,54(1):70-4.

RESUMO - Contexto - A cirurgia bariátrica se tornou o tratamento padrão-ouro para a obesidade mórbida, porém o acesso ao tratamento cirúrgico continua difícil e a baixa adesão ao seguimento pós-operatório é comum. Para melhorar os resultados e o índice de seguimento, nossa equipe propôs uma abordagem pré-operatória multidisciplinar para a cirurgia bariátrica. Objetivo - Determinar o impacto deste programa nos resultados da cirurgia bariátrica em um hospital público brasileiro. Métodos - Avaliação prospectiva dos indivíduos que passaram por um programa multidisciplinar pré-operatório para cirurgia bariátrica e comparação de seus resultados cirúrgicos com os observados no banco de dados históricos prospectivamente coletados antes do início do programa. Resultados - Houve 176 indivíduos que passaram pelo programa e 226 que não passaram. Os indivíduos que passaram pelo programa apresentaram frequência significativamente menor das seguintes variáveis: tempo de internação, deiscência de ferida, infecção de ferida, complicações pulmonares, fístulas anastomóticas, tromboembolismo pulmonar, hérnias incisionais, eventrações, reoperações e mortalidade. Tanto a perda de seguimento quanto a falência na perda de peso foram também significativamente menores entre aqueles que passaram pelo programa. Conclusão - A adoção de uma abordagem multidisciplinar pré-operatória integrada levou a melhoras significativas nos resultados pós-operatórios, e também na adesão ao acompanhamento pós-operatório, representando uma abordagem reprodutível e potencialmente benéfica dentro do contexto do sistema público de saúde do Brasil.

DESCRITORES - Obesidade. Cirurgia bariátrica. Derivação gástrica. Saúde pública. Cuidados pré-operatórios.

\section{REFERENCES}

1. Adams TD, Gress RE, Smith SC, Halverson RC, Simper SC, Rosamond WD, Lamonte MJ, Stroup AM, Hunt SC. Long-term mortality after gastric bypass surgery. N Engl J Med. 2007;357:753-61.

2. Alami RS, Morton JM, Schuster R, Lie J, Sanchez BR, Peters A, Curet MJ. Is there a benefit to preoperative weight loss in gastric bypass patients? A prospective randomized trial. Surg Obes Relat Dis. 2007;3:141-5.

3. Alvarado R, Alami RS, Hsu G, Safadi BY, Sanchez BR, Morton JM, Curet MJ. The impact of preoperative weight loss in patients undergoing laparoscopic Roux-en-Y gastric bypass. Obes Surg. 2005;15:1282-6.

4. Angrisani L, Santonicola A, Iovino P, Formisano G, Buchwald H, Scopinaro N. Bariatric Surgery Worldwide 2013. Obes Surg. 2015;25:1822-32.

5. Benotti PN, Still CD, Wood GC, Akmal Y, King H, El Arousy H, Dancea H, Gerhard GS, Petrick A, Strodel W. Preoperative weight loss before bariatric surgery. Arch Surg. 2009;144:1150-5.

6. Cazzo E, da Silva FP, Pareja JC, Chaim EA. Predictors for weight loss failure following Roux-en-Y gastric bypass. Arq Gastroenterol. 2014;51:328-30.

7. Chan AW, Hopkins J, Gagnon I, Birch DW. Improving access to bariatric surgery: early surgical and patient-focused outcomes of a rural obesity clinic. Am J Surg. 2016;211:938-42.e2.

8. Conaty EA, Bonamici NJ, Gitelis ME, Johnson BJ, DeAsis F, Carbray JM, Lapin B, Joehl R, Denham W, Linn JG, Haggerty SP, Ujiki MB. Efficacy of a Required Preoperative Weight Loss Program for Patients Undergoing Bariatric Surgery. J Gastrointest Surg. 2016;20:667-73.

9. Costa RC, Yamaguchi N, Santo MA, Riccioppo D, Pinto-Junior PE. Outcomes on quality of life, weight loss, and comorbidities after Roux-en-Y gastric bypass. Arq Gastroenterol. 2014;51:165-70.

10. Cuenca RM. Quality of life after bariatric surgery. Arq Gastroenterol. 2014;51:163-4.

11. Delgado Floody P, Cofré Lizama A, Alarcón Hormazábal M, Osorio Poblete A Caamaño Navarrete F, Jerez Mayorga D. Evaluation of a comprehensive program of four months of duration on the preoperative conditions of obese patients candidates for bariatric surgery. Nutr Hosp. 2015;32:1022-7.

12. Duarte MI, Bassitt DP, Azevedo OC, Waisberg J, Yamaguchi N, Pinto Junior PE. Impact on quality of life, weight loss and comorbidities: a study comparing the biliopancreatic diversion with duodenal switch and the banded Roux-en-Y gastric bypass. Arq Gastroenterol. 2014;51:320-7.

13. Fris RJ. Preoperative low energy diet diminishes liver size. Obes Surg. 2004; $14: 1165-70$

14. Gastrointestinal surgery for severe obesity: National Institutes of Health Consensus Development Conference Statement. Am J Clin Nutr. 1992;55(2 Suppl):615S-619S.

15. GlobalSurg Collaborative. Mortality of emergency abdominal surgery in high-, middle- and low-income countries. Br J Surg. 2016;103:971-88.
16. Halloran K, Padwal RS, Johnson-Stoklossa C, Sharma AM, Birch DW. Income status and approval for bariatric surgery in a publicly funded regional obesity program. Obes Surg. 2011;21:373-8.

17. Instituto Paulo Montenegro. INAF Brasil 2009: indicador de alfabetismo funcional. São Paulo: IBOPE. 2009:1-18.

18. Kelles SM, Machado CJ, Barreto SM. Ten-years of bariatric surgery in Brazil: in-hospital mortality rates for patients assisted by universal health system or a health maintenance organization. Arq Bras Cir Dig. 2014;27:261-7.

19. Larjani S, Spivak I, Hao Guo M, Aliarzadeh B, Wang W, Robinson S, Sockalingam S, Aarts MA. Preoperative predictors of adherence to multidisciplinary follow-up care postbariatric surgery. Surg Obes Relat Dis. 2016;12:350-6

20. Malta DC, Stopa SR, Iser BP, Bernal RT, Claro RM, Nardi AC, Reis AA, Monteiro CA. Risk and protective factors for chronic diseases by telephone survey in capitals of Brazil: Vigitel 2014. Rev Bras Epidemiol. 2015;18(Suppl 2):238-55.

21. Martin M, Beekley A, Kjorstad R, Sebesta J. Socioeconomic disparities in eligibility and access to bariatric surgery: a national population-based analysis. Surg Obes Relat Dis. 2010;6:8-15.

22. Memarian E, Calling S, Sundquist K, Sundquist J, Li X. Sociodemographic differences and time trends of bariatric surgery in Sweden 1990-2010. Obes Surg. 2014;24:2109-16.

23. NCD Risk Factor Collaboration (NCD-RisC). Trends in adult body-mass index in 200 countries from 1975 to 2014: a pooled analysis of 1698 population-based measurement studies with 19·2 million participants. Lancet. 2016;387:1377-96.

24. Pajecki D, Santo MA, Kanagi AL, Riccioppo D, de Cleva R, Cecconello I. Functional assessment of older obese patients candidates for bariatric surgery. Arq Gastroenterol. 2014;51:25-8.

25. Parikh M, Dasari M, McMacken M, Ren C, Fielding G, Ogedegbe G. Does a preoperative medically supervised weight loss program improve bariatric surgery outcomes? A pilot randomized study. Surg Endosc. 2012;26:853-61.

26. Patel P, Hartland A, Hollis A, Ali R, Elshaw A, Jain S, Khan A, Mirza S. Tier 3 multidisciplinary medical weight management improves outcome of Roux-en-Y gastric bypass surgery. Ann R Coll Surg Engl. 2015;97:235-7.

27. Ramos AC. Brazil looking for completing his space in bariatric surgery. Arq Bras Cir Dig. 2014;27 Suppl 1:1.

28. Reinhold RB. Critical analysis of long term weight loss following gastric bypass Surg Gynecol Obstet. 1982;155:385-94

29. Riess KP, Baker M, Lambert P, Mathiason MA, Kothari SN. Effect of preoperative weight loss of laparoscopic gastric bypass outcomes. Surg Obes Relat Dis. 2008; 4:704-8.

30. Still CD, Benotti P, Wood GC, Gerhard GS, Petrick A, Reed M, Strodel W Outcomes of preoperative weight loss in high-risk patients undergoing gastric bypass surgery. Arch Surg. 2007;142:994-8.

31. World Health Organization. Adherence to long term therapies: evidence for action. Geneva: WHO. 2003:1-211.

32. World Health Organization. Global status report on noncommunicable diseases 2014. Genebra: WHO. 2014: 1-298. 